\title{
Geoquímica de rios de água preta do sudeste do Amazonas: Origem, fluxo dos elementos e consumo de $\mathrm{CO}_{2}$
}

\author{
Anderson da Silva LAGES ${ }^{1}$, Adriana Maria Coimbra HORBE² e Jean-Sébastien MOQUET ${ }^{3}$
}

\begin{abstract}
RESUMO
Neste trabalho foi examinada a composição química das águas dos afluentes da margem direita do rio Madeira que drenam as rochas do Escudo Brasileiro. O estudo foi realizado no município de Apuí no sudeste do estado do Amazonas, Brasil. Foram analisados $\mathrm{pH}$, condutividade, as concentraçôes de $\mathrm{SiO}_{2}$ e de íons dissolvidos $\left(\mathrm{Na}^{+}, \mathrm{K}^{+}, \mathrm{Mg}^{2+}, \mathrm{Ca}^{2+}, \mathrm{HCO}_{3}^{-}, \mathrm{Cl}^{-}, \mathrm{NO}_{3}^{-}\right.$e $\mathrm{SO}_{4}^{2-}$ ) em quatro épocas do ano segundo o índice pluviométrico: chuvosa, transição para a estiagem, estiagem e transiçẫo para a chuvosa. As águas são diluídas, mais concentradas em $\mathrm{HCO}_{3}^{-}$e $\mathrm{SiO}_{2}$ e representam o típico ambiente de intensa lixiviação que afeta as rochas na Amazônia. Apesar da química das águas terem influência da sazonalidade, foram identificadas variaçôes em função da litologia. As taxas de exportação de cátions e de erosão química das rochas são baixas e refletem a estabilidade tectônica da região e o manto intempérico que dificulta a interação da água com o substrato rochoso.
\end{abstract}

PALAVRAS CHAVE: variação sazonal, exportação de cátions, erosão química.

\section{Geochemistry of black water rivers from the southeastern of the Amazonas State: source, element fluxes and consumption of $\mathrm{CO}_{2}$}

\section{ABSTRACT}

This work examined the chemical composition of waters from tributaries of the right bank of the Madeira River which drain silicaterocks of the Brazilian Craton. The study was conducted at the municipalityof Apui, in the southeastern of the Amazonas State, Brazil. There were analyzed $\mathrm{pH}$, conductivity, $\mathrm{SiO}_{2}$ and dissolved ions $\left(\mathrm{Na}^{+}, \mathrm{K}^{+}, \mathrm{Mg}^{2+}\right.$ e $\mathrm{Ca}^{2+}, \mathrm{HCO}_{3}^{-}, \mathrm{Cl}^{-}, \mathrm{NO}_{3}^{-}$and $\mathrm{SO}_{4}^{2-}$ ) in the four pluviometric seasons of the Amazon region: rainy, transition to the dry, dry and transition to the rainy. The waters are diluted, have high $\mathrm{HCO}_{3}$ and $\mathrm{SiO}_{2}$ concentration and represent the typical environment of intense leaching that affects the rocks in the Amazon. Although the chemical composition reveals seasonal influences, it was identified variation due to lithological composition. The rate of exportation of cations and the chemical erosion are low in consequence of the tectonic stability of the region and the weathering mantle, which hinders the interaction of water with the bedrock.

KEYWORDS: seasonal variability, cation exportation rate, chemical erosion.

\footnotetext{
1 Programa de pós-graduação em Geociências, Universidade Federal do Amazonas, as.lages@hotmail.com;

2 Departamento de Geociências, Universidade Federal do Amazonas, ahorbe@ufam.edu.br; Av. Rodrigo Otávio Jordão Ramos 3000, Manaus, 69050-290, Amazonas, Brasil;

3 Instituto de Geociências, Universidade de São Paulo, js.moquet@gmail.com, Rua do Lago, 562 - Cidade Universitária, São Paulo, 05508-080.
} 


\section{INTRODUÇÃO}

As rochas são as principais fontes de elementos químicos para as águas em ambientes naturais, apesar de aerossóis marinhos, poeiras, vegetação e a ação antrópica terem forte influência (Maybeck 2003). Dentre as rochas, os carbonatos e os evaporitos, por serem facilmente lixiviados, são as que mais rapidamente liberam elementos químicos para as águas (Drever 1997). Por exemplo, a alcalinidade das águas $\left(\mathrm{HCO}_{3}{ }^{-}\right)$ está relacionada ao $\mathrm{CO}_{2}$ liberado pelos carbonatos. Quando ausentes, a alcalinidade é menor, pois é derivada unicamente do $\mathrm{CO}_{2}$ da atmosfera que é incorporado ao solo pela matéria orgânica (Picouet et al. 2002) e liberado para as águas quando estas o percolam. Os carbonatos, geralmente de $\mathrm{Ca}$ e $\mathrm{Mg}$ $\left((\mathrm{Ca}, \mathrm{Mg}) \mathrm{CO}_{3}\right)$, são por conseguinte a principal fonte natural desses elementos e a gipsita $\left(\mathrm{CaSO}_{4} \cdot 2 \mathrm{H}_{2} \mathrm{O}\right)$ presente nos evaporitos, de $\mathrm{Ca}$ e $\mathrm{SO}_{4}$. A relação desses elementos com as rochas é determinada com base na correlação positiva entre $\mathrm{Ca}+\mathrm{Mg}$ versus $\mathrm{HCO}_{3}$ quando relacionados aos carbonatos e entre $\mathrm{Ca}$ e $\mathrm{SO}_{4}$ quando relacionados a gipsita. Razóes elevadas de $\mathrm{Mg} / \mathrm{Ca}$ indicam intemperismo de dolomita, enquanto que de $\mathrm{Ca} / \mathrm{Mg}$ indicam intemperismo de calcita. Essas relações são exemplificadas pela reação de dissoluçáo: $\mathrm{CaMg}\left(\mathrm{CO}_{3}\right)_{2}+$ $\mathrm{CaSO}_{4} \cdot 2 \mathrm{H}_{2} \mathrm{O}+\mathrm{CO}_{2}=\leftrightarrow \mathrm{Ca}^{2+}+\mathrm{Mg}^{2+}+2 \mathrm{HCO}_{3}^{-}+\mathrm{SO}_{4}^{2-}+$ $\mathrm{H}_{2} \mathrm{O}$. Outra fonte de $\mathrm{SO}_{4}$ são os sulfetos segundo a reação: $2 \mathrm{FeS}_{2}+2 \mathrm{H}_{2} \mathrm{O}+7 \mathrm{O}_{2} \leftrightarrow 2 \mathrm{Fe}^{3+}+2 \mathrm{SO}_{4}^{2-}+2 \mathrm{H}_{2} \mathrm{SO}_{4}$ que na presença de água gera ambiente ácido (Drever 1997, Picouet et al. 2002, Smolders et al. 2004).

$\mathrm{O}$ conteúdo de $\mathrm{Cl}^{-}$nas águas está relacionado, principalmente aos evaporitos, pois nos demais tipos de rochas sua concentração é extremamente baixa (Drever 1997). Como a fonte dos evaporitos é a água do mar, a razão $\mathrm{Na} /$ $\mathrm{Cl}$ na água próxima a 1 representa influência desse tipo de rocha (Berner e Berner 1987). Contudo, $\mathrm{Na}$ e Cl também podem ser relacionados à precipitação, neste caso o aporte pode ser medido analisando água da chuva e corrigindo em relação a água do mar (Stallard e Edmond 1983 e Gaillardet et al. 1997). Outra característica que permite inferir a rocha fonte é a carga positiva, águas originadas do intemperismo de silicatos possuem $\sum+<0,185$ meq $\mathrm{L}^{-1}$, enquanto as salinas $>24$ meq L $\mathrm{L}^{-1}$ (Maybeck 2003). O longo intemperismo a que estáo submetidas as rochas dos escudos gera caulinita e gibbsita e aumenta a concentraçáo de $\mathrm{SiO}_{2}$ nas águas, neste caso tende a ter $\mathrm{Si}: \Sigma^{+}<4$ e Si: $(\mathrm{Na}+\mathrm{K})<3$ (Edmond et al. 1995).

Em regiôes pouco habitadas e ainda a salvo da contaminação é possível, por meio do estudo da química das águas, construir modelos geoquímicos sobre a interação entre litologia, clima, relevo e intemperismo e determinar o fluxo e a taxa de elementos liberados das rochas bem como o consumo de $\mathrm{CO}_{2}$ (Stallard e Edmond 1987, Edmond et al. 1995, Gaillardet et al. 1997, entre outros). Alguns trabalhos, nessa linha de estudo, já foram realizados na Amazônia como os de Allègre et al.
(1996), Gaillardet et al. (1997), Mortatti e Probst (2003) entre outros. Com o objetivo de determinar as influências sazonais e do porte das drenagens, o fluxo dos elementos liberados, a taxa de erosão e o consumo de $\mathrm{CO}_{2}$ durante o intemperismo de rochas do Escudo Brasileiro, foram selecionados seis rios e dois igarapés na região SE do Amazonas.

\section{MATERIAL E MÉTODOS}

\section{Área de Estudo}

Os rios selecionados neste estudo pertencem a duas bacias hidrológicas principais, as dos rios Sucunduri-Canumá a leste e Aripuanã a oeste (Figura 1). A primeira bacia tem aproximadamente $650 \mathrm{~km}$ de extensão norte-sul, as nascentes se encontram próximas ao limite com o Estado do Mato Grosso e deságua no baixo curso do rio Madeira, próximo à cidade de Nova Olinda. Seus principais afluentes são os rios Acari, com extensão aproximada de $240 \mathrm{~km}$, Camaiú com $180 \mathrm{~km}$, além do próprio Sucunduri, que se estende por mais de $150 \mathrm{~km}$ com inúmeras cachoeiras e nascentes próximas à divisa do Amazonas com o Mato Grosso. Esses três rios são cortados pela BR-230 e nos locais estudados, possuem larguras de aproximadamente $50 \mathrm{~m}, 30 \mathrm{~m}$ e $80 \mathrm{~m}$, respectivamente. A bacia do rio Aripuaná, localiza-se a oeste da área, tem direção geral N-S, nascentes no Estado do Mato Grosso e Rondônia e deságua no rio Madeira à montante da cidade de Manicoré totalizando aproximadamente $750 \mathrm{~km}$ de extensão (Figura 1). No local amostrado o rio Aripuaná tem, aproximadamente $350 \mathrm{~m}$ de largura. Os rios Jatuarana, com $260 \mathrm{~km}$ de extensão e o Juma, com $240 \mathrm{~km}$, são afluentes menores (Figura 1) e nos locais onde são cortados pela BR-230 possuem aproximadamente $30 \mathrm{~m}$ de largura. Os locais amostrados nos rios Aripuanã, Acari e Sucunduri estáo nas proximidades das estaçóes hidrológicas dos respectivos rios. Os dados de vazáo e da área da bacia estáo em www.ore-hybam.org.

Ambas as bacias drenam as rochas do Escudo Brasileiro e em seus baixos cursos, próximos a confluência com o rio Madeira, as rochas sedimentares da bacia do Amazonas (Formações Içá e Alter do Chão) (Figura 1). O Escudo Brasileiro no SE do Amazonas é constituído pelo Grupo Alto Tapajós e Grupo Colíder (Reis 2006) (Figura 1). O Grupo Alto Tapajós é formado por siltitos, arenitos, pelitos, brechas silicosas e, localmente, calcários cinza escuros no alto rio Sucunduri. O Grupo Colíder, composto por rochas vulcânicas ácidas, tem ocorrência restrita a porção $\mathrm{SW}$ da área e tem influência direta nos rios Aripuanã e Acari. Todas essas rochas foram lateritizadas e esculpidas pela drenagem desenvolvendo platôs e colinas com cota inferior a $300 \mathrm{~m}$.

A regiáo está totalmente sob a influência da floresta tropical. O clima é quente e úmido com estiagem pouco pronunciada. A temperatura anual média varia entre $25^{\circ}$ e $27^{\circ}$ 


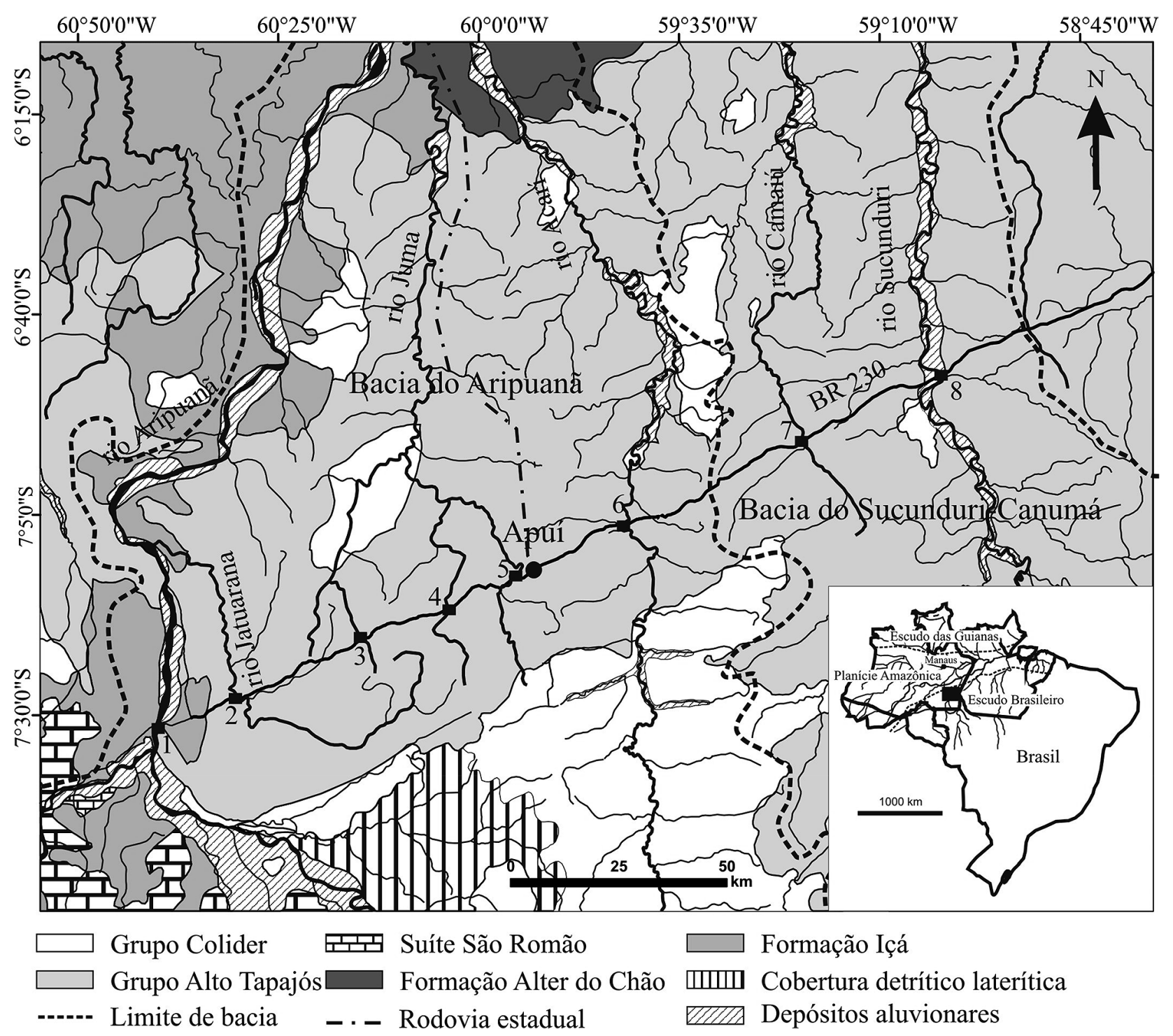

Figura 1 - Mapa de localização das drenagens analisadas e geologia da área (1-rio Aripuanã, 2- rio Jatuarana, 3- igarapé 1, 4- igarapé 2, 5- rio Juma, 6- rio Acari, 7- rio Camaiú e 8- rio Sucunduri). Em detalhe mapa do Brasil com o limite entre os macroambientes geológicos onde se insere a área estudada.

C. A umidade relativa do ar é de aproximadamente $85 \%$ e a precipitação chega até $2200 \mathrm{~mm}^{2}$ ano $^{-1}$. Segundo levantamento pluviométrico de dez anos (1998 e 2007) realizado pela Agência Nacional de Águas, o período chuvoso se extende de outubro a abril (máximo de $300 \mathrm{~mm} \mathrm{mês}^{-1}$ ), maio é a transição para a estiagem (155 mm mês $\left.{ }^{-1}\right)$, o período mais seco está entre junho e agosto (até $72 \mathrm{~mm}$ mês ${ }^{-1}$ ) e setembro caracteriza o período de transição para o chuvoso (até $160 \mathrm{~mm} \mathrm{mês}^{-1}$ ).

\section{Coleta de material e análises químicas}

As coletas de água dos rios foram mensais, realizadas entre abril de 2009 e janeiro de 2010. Foram selecionadas as drenagens de maior porte que cortam a rodovia BR 230 (Transamazônica) entre os rios Aripuanã e Sucunduri
(Figura 1) localizados nos km 540 e 750, respectivamente. Nesse trecho foram amostrados, além dos rios Aripuanã (1) e Sucunduri (8), o Jatuarana (2), Juma (5), Acari (6), Camaiú (7) e duas drenagens menores Ig1 (3) e Ig2 (4) afluentes dos rios Jatuarana e Juma, respectivamente (Figura 1).

Com base nos dados de pluviometria, as amostras mensais foram agrupadas em quatro períodos sazonais: chuvoso (média dos meses abril, outubro, novembro, dezembro e janeiro - náo foram amostrados os meses de fevereiro e março), de transição para a estiagem (maio), estiagem (junho, julho, agosto) e de transição para o chuvoso (setembro).

As amostras foram coletadas no centro do rio a $20 \mathrm{~cm}$ de profundidade, com auxílio de uma canoa, nos rios Aripuanã 
e Sucunduri, nos demais, onde há ponte, esta foi utilizada como apoio. Cada amostra foi coletada com uma seringa de $100 \mathrm{ml}$ e filtrada em um millex de $0,45 \mu \mathrm{m}$ de poro e acondicionada em frasco de polietileno, previamente colocado por 24 hs em solução de $\mathrm{HNO}_{3}$ a $10 \%$ e lavados com água purificada por sistema Milli Q. Para evitar a ação bacteriana que modificasse a composição química da água foi adicionado, aproximadamente $0,02 \mathrm{~g}$ de timol (Santos 2009).

$\mathrm{O} \mathrm{pH}$ foi medido com o auxílio de um pHmetro digital, previamente calibrado com soluçôes tampóes de $\mathrm{pH}$ 7,0 e 4,0 respectivamente. A condutividade elétrica foi determinada com condutivímetro digital calibrado com solução $0,1 \mathrm{~N}$ de $\mathrm{KCl}$, a $12,9 \mathrm{Ms} \mathrm{cm}^{-1}$. A alcalinidade foi determinada por volumetria de neutralização, utilizando ácido sulfúrico na concentração de $0,02 \mathrm{~N}$ até $\mathrm{pH} 4,3$ e expressa em miligramas de $\mathrm{HCO}_{3}$. $\mathrm{A} \mathrm{SiO}_{2}$ foi determinada por espectrofotometria e cátions $\left(\mathrm{Na}^{+}, \mathrm{K}^{+}, \mathrm{Mg}^{2+} \mathrm{e} \mathrm{Ca}{ }^{2+}\right)$ e ânions $\left(\mathrm{Cl}, \mathrm{NO}_{3}{ }^{-}\right.$e $\left.\mathrm{SO}_{4}^{2-}\right)$ por cromatografia de íons (DIONEX ICS 900) no laboratório de Geoquímica da UFAM.

O total de sólidos dissolvidos (TDS) foi calculado a partir $\mathrm{Na}^{+}+\mathrm{K}^{+}+\mathrm{Mg}^{2+}+\mathrm{Ca}^{2+}+\mathrm{Cl}^{-}+\mathrm{SO}_{4}{ }^{2+}+\mathrm{HCO}_{3}+\mathrm{NO}_{3}+\mathrm{SiO}_{2} \mathrm{em} \mathrm{\mu g} \mathrm{L^{-1 }}$ e a normalização do balanço das cargas inorgânicas (NBCI) segundo a equação $\left[\left(\Sigma \mu \mathrm{eq}^{+} \mathrm{L}^{-1}-\Sigma \mu \mathrm{eq}^{-} \mathrm{L}^{-1}\right) /\left[\left(\Sigma \mu \mathrm{eq}^{+} \mathrm{L}^{-1}+\Sigma \mu \mathrm{eq}\right.\right.\right.$ $\left.\left.\mathrm{L}^{-1}\right)\right] / 2$ onde $\Sigma\left(\mu \mathrm{eq}^{+} \mathrm{L}^{-1}\right)=\mathrm{Na}^{+}+\mathrm{K}^{+}+2\left(\mathrm{Ca}^{2+}+\mathrm{Mg}^{2+}\right)$ e $\Sigma\left(\mu \mathrm{eq}^{-} \mathrm{L}^{-1}\right)$ $=\mathrm{HCO}_{3}{ }^{-}+\mathrm{Cl}+2 \mathrm{SO}_{4}{ }^{2-}+\mathrm{NO}_{3}{ }^{-} \mathrm{em} \mu \mathrm{g} \mathrm{L}{ }^{-1}$.

\section{RESULTADOS}

\section{Parâmetros físicos e químicos}

$\mathrm{O} \mathrm{pH}$ e a condutividade mostram que as águas menos ácidas e mais condutivas estáo na transição para o período chuvoso (5,3 a 7,2 e 18,0 a $33,5 \mu S \mathrm{~cm}^{-1}$, respectivamente) (Tabela 1 e Figura 2), enquanto as mais ácidas estão no período chuvoso $(4,0$ a 4,9) e na transição para a estiagem $(3,7$ a 4,9).
As menos condutivas estâo na transição para a estiagem $(8,2$

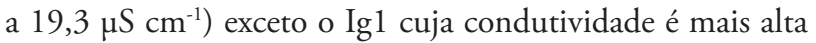
nesse período $\left(28,0 \mu \mathrm{S} \mathrm{cm}^{-1}\right)$.

A composição química e, consequentemente a contribuição de cada íon é variável entre os períodos analisados e entre as drenagens (Tabela 1, Figura 2). Contudo o $\mathrm{HCO}_{3}{ }^{-}$é o íon mais abundante na maioria das águas dos rios de Apuí (entre $<200$ e $14.887 \mu \mathrm{g} \mathrm{L}^{-1}$ ) exceto nas do Aripuanã mais concentradas no período chuvoso e nas do Acari com pouca variaçáo ao longo do período hidrológico. $\mathrm{O} \mathrm{SiO}_{2}$ é o componente mais abundante nos períodos chuvoso e transição para a estiagem (entre 2.422 e $5580 \mu \mathrm{g} \mathrm{L}^{-1}$ ) quando o $\mathrm{HCO}_{3}^{-}$está abaixo do limite de detecçáo, devido ao $\mathrm{pH}$ mais ácido das águas (Tabela 1 e Figura 1). Nota-se ainda que $\mathrm{K}^{+}, \mathrm{Mg}^{2+}, \mathrm{Ca}^{2+}$ e Cl tendem a maior concentração no período de transição para o chuvoso (exceto as águas do Jatuarana com $\mathrm{Ca}^{2+}$ excepcionalmente elevado na transição para a estiagem e as do Acari e Camaiú com mais $\mathrm{K}^{+}$no período chuvoso). Os outros íons têm comportamento mais diferenciado e dentre eles o $\mathrm{Na}^{+}$tende a ser mais concentrado na estiagem, especialmente nas águas do Aripuanã e Camaiú, e no chuvoso nas do Acari, Ig2 e Juma (Figura 2). $\mathrm{O} \mathrm{NO}_{3}^{-}$nas águas do Aripuanâ, na transição para a estiagem $\left(5426 \mu \mathrm{g} \mathrm{L} \mathrm{L}^{-1}\right)$, é quase o dobro da concentração em relação as demais drenagens. Também é elevado no período chuvoso nas águas do Camaiu e Ig2 (Tabela 1 e Figura 1). O conteúdo de $\mathrm{SO}_{4}^{2-}$ assemelha-se ao de $\mathrm{K}^{+}$, mas com dispersão mais acentuada na transição para o chuvoso e o Juma destacase por possuir a maior concentração $\left(440 \mu \mathrm{g} \mathrm{L}^{-1}\right)$ na transiçáo para a estiagem (Tabela 1 e Figura 2).

$\mathrm{O}$ predomínio de $\mathrm{HCO}_{3}^{-}$e $\mathrm{SiO}_{2}$ sobre os demais íons permite classificar as águas como sendo bicarbonatadassilícicas, apesar do $\mathrm{K}^{+}$e $\mathrm{NO}_{3}{ }^{-}$também serem abundantes no período chuvoso no Acarí e Camaiú, o $\mathrm{Ca}^{2+}$ no Jatuarana na

Tabela 1 - Valores médios dos parâmetros analisados por período sazonal, ponderados pela pluviosidade (condutividade em $\mu \mathrm{S} \mathrm{cm}{ }^{-1}$, TDS em mg L-1, íons e $\mathrm{SiO}_{2}$ em $\mu \mathrm{g} \mathrm{L}^{-1}$ e somatória de cátions $\left(\Sigma^{+}\right)$e ânions $\left(\Sigma^{-}\right)$em $\mu$ eq L-1).

\begin{tabular}{|c|c|c|c|c|c|c|c|c|c|c|}
\hline & & Aripuanã & Jatuarana & $\lg 1$ & $\lg , 2$ & Juma & Acari & Camaiú & Sucundurí & Média \\
\hline \multirow{15}{*}{ 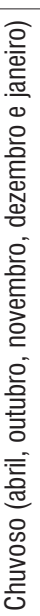 } & $\mathrm{pH}$ & 4,9 & 4,5 & 4,0 & 3,9 & 4,2 & 4,8 & 4,4 & 4,2 & --- \\
\hline & CE & 22,2 & 16,9 & 13,7 & 13,3 & 10,7 & 24,9 & 19,8 & 19,5 & 18,2 \\
\hline & $\mathrm{Na}^{+}$ & $1.141,4$ & 124,0 & 135,3 & 620,5 & 641,7 & $1.231,3$ & 210,7 & 283,6 & 548,6 \\
\hline & $\mathrm{K}^{+}$ & $1.635,9$ & 716,3 & 727,5 & 911,6 & $1.437,0$ & $2.286,4$ & $2.574,9$ & $1.259,1$ & $1.443,6$ \\
\hline & $\mathrm{Ca}^{2+}$ & $1.042,3$ & 801,1 & 245,9 & 369,3 & 719,6 & 762,7 & 207,3 & $1.054,5$ & 650,4 \\
\hline & $\mathrm{Mg}^{2+}$ & 465,5 & 328,6 & 163,4 & 98,1 & 248,7 & 336,1 & 200,2 & 564,4 & 300,6 \\
\hline & $\mathrm{SiO}_{2}$ & $5.001,4$ & $2.918,1$ & $2.421,6$ & $2.488,6$ & $2.874,1$ & $5.274,3$ & $2.970,5$ & $3.482,7$ & $3.428,9$ \\
\hline & $\mathrm{HCO}_{3}$ & $14.887,4$ & $5.470,1$ & $<200,0$ & $<200,0$ & $<200,0$ & $11.968,6$ & $8.927,2$ & $<200,0$ & $5.156,7$ \\
\hline & $\mathrm{Cl}^{-}$ & 330,8 & 274,1 & 264,3 & 291,2 & 330,7 & 298,2 & 305,5 & 253,6 & 293,5 \\
\hline & $\mathrm{NO}_{3}^{-}$ & 427,1 & 407,1 & 480,4 & $2.059,1$ & 973,6 & 498,4 & $2.365,5$ & $1.380,0$ & $1.073,9$ \\
\hline & $\mathrm{SO}_{4}^{2-}$ & 189,9 & 270,8 & 81,5 & 156,5 & 177,6 & 235,5 & 206,4 & 189,8 & 188,5 \\
\hline & TDS & 25,1 & 11,3 & 4,5 & 7,0 & 7,4 & 22,9 & 18,0 & 8,5 & 13,1 \\
\hline & $\Sigma^{+}$ & $5.792,9$ & $3.099,9$ & $1.681,6$ & $2.467,0$ & $4.015,3$ & $5.715,3$ & $3.600,6$ & $4.780,7$ & $3.894,2$ \\
\hline & $\Sigma$ & $16.025,0$ & $6.692,9$ & 907,5 & $2.663,3$ & $1.659,5$ & $13.236,2$ & $12.011,1$ & $2.013,3$ & $6.901,1$ \\
\hline & $\mathrm{NBCl}$ & $-0,23$ & $-0,18$ & 0,15 & $-0,02$ & 0,21 & $-0,20$ & $-0,27$ & 0,20 & $-0,04$ \\
\hline
\end{tabular}


Tabela 1 - Continuação

\begin{tabular}{|c|c|c|c|c|c|c|c|c|c|c|}
\hline & & Aripuanã & Jatuarana & $\lg 1$ & $\lg , 2$ & Juma & Acari & Camaiú & Sucundurí & Média \\
\hline \multirow{15}{*}{ 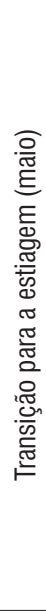 } & $\mathrm{pH}$ & 4,9 & 4,3 & 3,2 & 3,7 & 4,2 & 4,8 & 4,4 & 4,3 & --- \\
\hline & CE & 18,0 & 11,2 & 28,0 & 8,3 & 9,2 & 19,3 & 8,2 & 12,4 & 14,3 \\
\hline & $\mathrm{Na}^{+}$ & 942,0 & 40,0 & 46,0 & 409,0 & 72,0 & 686,0 & 115,0 & 159,0 & 308,6 \\
\hline & $\mathrm{K}^{+}$ & $1.019,0$ & 488,0 & 573,0 & 409,0 & 878,0 & 980,0 & 315,0 & 792,0 & 681,8 \\
\hline & $\mathrm{Ca}^{2+}$ & 889,7 & $2.949,5$ & 57,8 & 47,7 & 426,2 & 521,8 & 69,8 & 249,3 & 651,5 \\
\hline & $\mathrm{Mg}^{2+}$ & 591,4 & 354,3 & 150,0 & 157,3 & 312,7 & 400,1 & 112,3 & 374,1 & 306,5 \\
\hline & $\mathrm{SiO}_{2}$ & $5.640,0$ & $5.260,0$ & $5.220,0$ & $4.910,0$ & $5.580,0$ & $5.250,0$ & $2.350,0$ & $3.670,0$ & $4.735,0$ \\
\hline & $\mathrm{HCO}_{3}$ & $12.200,0$ & $<200,0$ & $<200,0$ & $<200,0$ & $<200,0$ & $9.760,0$ & $2.440,0$ & $<200,0$ & $3.050,0$ \\
\hline & $\mathrm{Cl}^{-}$ & 147,0 & 95,0 & 189,0 & 131,0 & 194,0 & 68,0 & 485,0 & 42,0 & 168,9 \\
\hline & $\mathrm{NO}_{3}^{-}$ & $5.426,0$ & 485,0 & $1.209,0$ & $1.708,0$ & 107,4 & 329,0 & 140,0 & 325,0 & $1.216,2$ \\
\hline & $\mathrm{SO}_{4}^{2-}$ & 79,0 & 112,0 & 53,0 & 53,0 & 440,0 & 19,0 & 19,0 & 36,0 & 101,4 \\
\hline & TDS & 26,9 & 9,8 & 7,5 & 7,8 & 8,0 & 18,0 & 6,0 & 5,6 & 11,2 \\
\hline & $\Sigma^{+}$ & $4.923,1$ & $7.135,6$ & $1.034,6$ & $1.228,0$ & $2.427,7$ & $3.509,8$ & 794,1 & $2.197,7$ & $2.906,3$ \\
\hline & $\Sigma$ & $17.931,0$ & 804,0 & $1.504,0$ & $1.945,0$ & $1.181,4$ & $10.195,0$ & $3.103,0$ & 439,0 & $4.637,8$ \\
\hline & $\mathrm{NBCl}$ & $-0,28$ & 0,40 & $-0,09$ & $-0,11$ & 0,17 & $-0,24$ & $-0,30$ & 0,33 & $-0,02$ \\
\hline \multirow{15}{*}{ 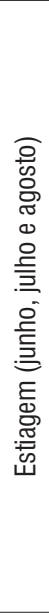 } & $\mathrm{pH}$ & 5,9 & 5,1 & 4,6 & 4,7 & 5,0 & 5,7 & 4,9 & 5,6 & --- \\
\hline & CE & 21,2 & 18,8 & 13,5 & 13,4 & 17,4 & 21,6 & 11,5 & 20,4 & 17,2 \\
\hline & $\mathrm{Na}^{+}$ & $1.346,3$ & 144,1 & 299,9 & 215,2 & 385,2 & 935,9 & 818,3 & 250,0 & 549,4 \\
\hline & $\mathrm{K}^{+}$ & $1.391,5$ & $1.096,0$ & 856,9 & 852,8 & 1448,6 & $1.825,0$ & $1.210,1$ & $1.389,6$ & $1.258,8$ \\
\hline & $\mathrm{Ca}^{2+}$ & $1.166,4$ & $1.177,1$ & 183,6 & 52,0 & 683,2 & 812,1 & 179,3 & $1.200,3$ & 681,8 \\
\hline & $\mathrm{Mg}^{2+}$ & 650,9 & 861,2 & 153,6 & 159,3 & 515,3 & 557,1 & 154,7 & $1.004,8$ & 507,1 \\
\hline & $\mathrm{SiO}_{2}$ & $7.062,9$ & $4.804,9$ & $3.658,9$ & $3.919,0$ & $5.589,6$ & $9.810,0$ & $4.253,1$ & $4.979,4$ & $5.509,7$ \\
\hline & $\mathrm{HCO}_{3}$ & $10.077,7$ & $8.069,3$ & $5.326,4$ & $5.094,4$ & $9.040,3$ & $12.200,0$ & $4.265,5$ & $12.685,2$ & $8.344,8$ \\
\hline & $\mathrm{Cl}^{-}$ & 332,5 & 158,1 & 164,9 & 206,4 & 204,8 & 128,9 & 144,0 & 108,7 & 181,0 \\
\hline & $\mathrm{NO}_{3}^{-}$ & 314,5 & 301,6 & 71,1 & 191,0 & 415,9 & 687,0 & 229,6 & 272,7 & 310,4 \\
\hline & $\mathrm{SO}_{4}^{2-}$ & 168,8 & 164,9 & 213,8 & 226,7 & 108,1 & 146,5 & 167,3 & 138,9 & 166,9 \\
\hline & TDS & 23,0 & 16,8 & 10,9 & 10,9 & 18,4 & 27,1 & 11,4 & 22,0 & 17,5 \\
\hline & $\Sigma^{+}$ & $6.372,6$ & $5.316,8$ & $1.831,0$ & $1.490,7$ & $4.230,8$ & $5.499,3$ & $2.696,4$ & $6.049,7$ & $4.185,9$ \\
\hline & $\Sigma$ & $11.062,2$ & $8.858,7$ & $5.989,9$ & $5.945,0$ & $9.877,2$ & $13.308,8$ & $4.973,9$ & $13.344,5$ & $9.170,0$ \\
\hline & $\mathrm{NBCl}$ & $-0,13$ & $-0,12$ & $-0,27$ & $-0,30$ & $-0,20$ & $-0,21$ & $-0,15$ & $-0,19$ & 0,20 \\
\hline \multirow{15}{*}{ 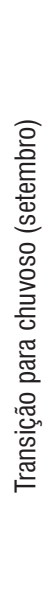 } & $\mathrm{pH}$ & 7,2 & 6,5 & 5,4 & 5,3 & 6,5 & 6,6 & 6,0 & 7,1 & --- \\
\hline & CE & 26,7 & 26,5 & 23,2 & 18,0 & 19,7 & 33,5 & 22,6 & 32,8 & 25,4 \\
\hline & $\mathrm{Na}^{+}$ & 951,8 & 326,8 & 306,7 & 444,9 & 314,5 & $1.151,0$ & 330,1 & 273,0 & 512,4 \\
\hline & $\mathrm{K}^{+}$ & $1.707,6$ & $1.804,8$ & $1.009,1$ & $1.429,9$ & $1.995,5$ & 24,1 & $1.784,1$ & $1.665,0$ & $1.427,5$ \\
\hline & $\mathrm{Ca}^{2+}$ & $1.410,8$ & $1.550,6$ & 123,2 & 192,7 & 864,5 & $1.075,5$ & 163,4 & $1.882,1$ & 907,9 \\
\hline & $\mathrm{Mg}^{2+}$ & 762,9 & $1.061,7$ & 211,6 & 247,2 & 663,3 & 659,4 & 224,9 & $1.526,9$ & 669,7 \\
\hline & $\mathrm{SiO}_{2}$ & $2.230,0$ & $3.580,0$ & $1.670,0$ & $2.940,0$ & $3.990,0$ & $6.580,0$ & $2.890,0$ & $3.920,0$ & $3.475,0$ \\
\hline & $\mathrm{HCO}_{3}$ & $10.980,0$ & $10.004,0$ & $8.296,0$ & $8.052,0$ & $10.004,0$ & $10.248,0$ & $9.272,0$ & $10.980,0$ & $9.729,5$ \\
\hline & $\mathrm{Cl}^{-}$ & 612,3 & 934,8 & 661,0 & $1.040,4$ & 609,9 & 831,7 & 883,1 & 492,7 & 758,2 \\
\hline & $\mathrm{NO}_{3}^{-}$ & $1.254,4$ & $1.008,4$ & 140,3 & 240,8 & 656,6 & $1.270,0$ & $1.050,5$ & $1.326,9$ & 868,5 \\
\hline & $\mathrm{SO}_{4}{ }^{2-}$ & 236,4 & 67,9 & 279,9 & 186,5 & 115,7 & 127,2 & 32,2 & 285,6 & 166,4 \\
\hline & TDS & 20,1 & 20,3 & 12,7 & 14,8 & 19,2 & 22,0 & 16,7 & 22,4 & 18,5 \\
\hline & $\Sigma^{+}$ & $7.006,8$ & $7.356,2$ & $1.985,4$ & $2.754,6$ & $5.365,6$ & $4.644,9$ & $2.890,8$ & $8.756,0$ & $5.095,0$ \\
\hline & $\Sigma$ & $13.319,5$ & $12.083,0$ & $9.657,1$ & $9.706,2$ & $11.501,9$ & $1.2604,1$ & $11.270,0$ & $13.370,8$ & $11.689,1$ \\
\hline & $\mathrm{NBCl}$ & $-0,16$ & $-0,12$ & $-0,33$ & $-0,28$ & $-0,18$ & $-0,23$ & $-0,30$ & $-0,10$ & $-0,21$ \\
\hline
\end{tabular}

$\mathrm{TDS}=\mathrm{Na}^{+}+\mathrm{K}^{+}+\mathrm{Mg}^{2+}+\mathrm{Ca}^{2+}+\mathrm{SiO}_{2}+\mathrm{Cl}^{+}+\mathrm{HCO}_{3}{ }^{-}+\mathrm{NO}_{3}{ }^{-}+\mathrm{SO}_{4}{ }^{2-}$. Normalização do balanço de cargas inorgânicas $(\mathrm{NBCl})=\left(\left(\Sigma \mu\right.\right.$ eq L $\mathrm{L}^{-1}$ cátions- $\Sigma \mu$ eq L-1 ânions $) / \Sigma \mu$ eq $\mathrm{L}^{-1}$ cátions a partir de $\left.\mu \mathrm{g} \mathrm{L}^{-1}\right)$.

transição para a estiagem e o $\mathrm{Cl}^{-}$no $\mathrm{Ig} 2$ na transição para o chuvoso (Tabela 1). Essas variaçóes, por não serem constantes ao longo do período analisado, sugerem que, além do volume de água, fatores locais e complexos como aporte de tributários, turbulência, fotossíntese, atividade biológica, quantidade de material em suspensão, tipo, composição (mineralogia, 

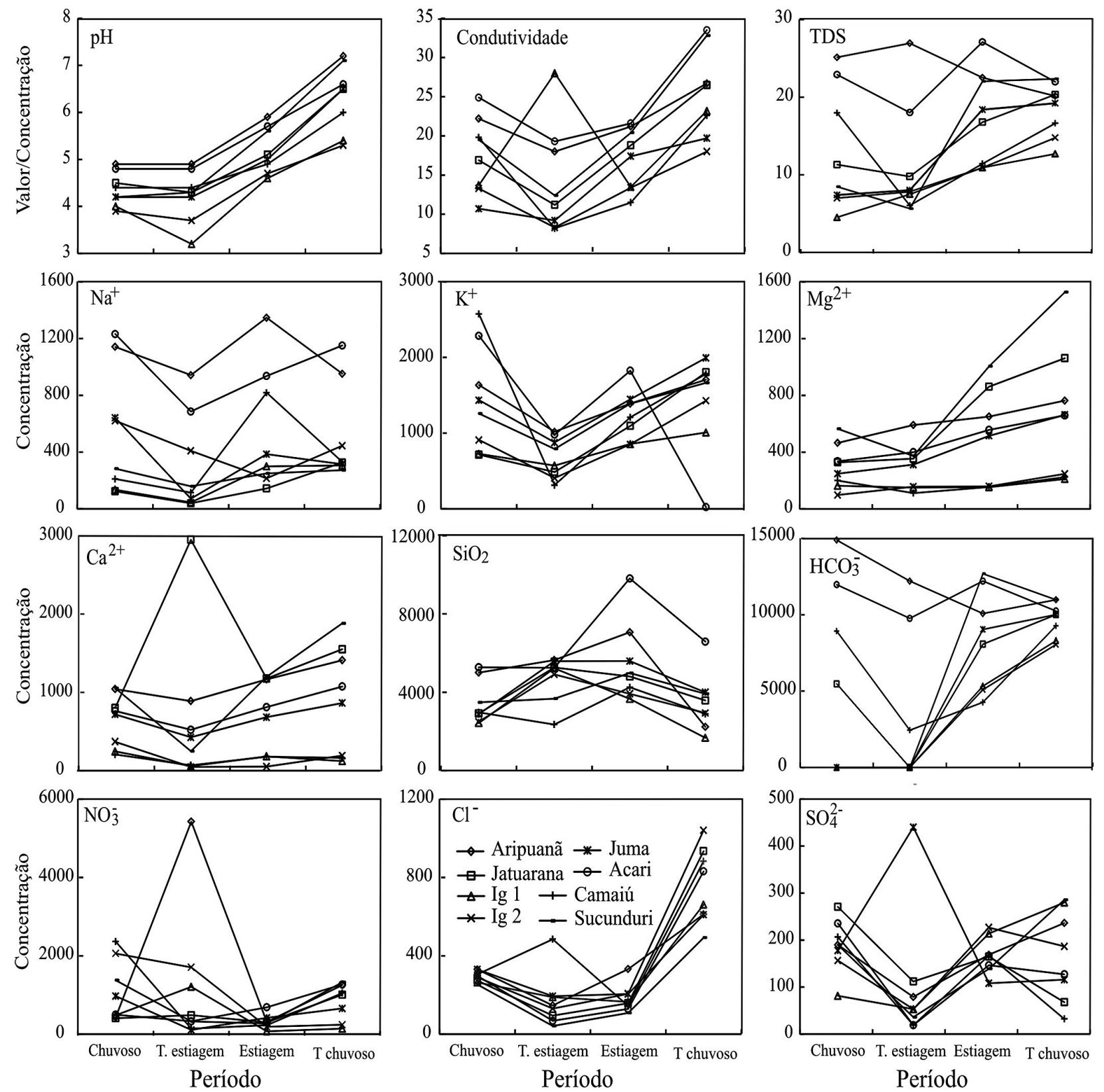

Figura 2 - Distribuição de $\mathrm{pH}$, condutividade em $\mu \mathrm{S} \mathrm{cm}^{-1}$, TDS (total de sólidos dissolvidos $=\mathrm{Na}^{+}+\mathrm{K}^{+}+\mathrm{Mg}^{2+}+\mathrm{Ca}^{2+}+\mathrm{Cl}^{-}+\mathrm{SO}_{4}^{2+}+\mathrm{HCO}_{3}^{-}+\mathrm{NO}_{3}^{-}+\mathrm{SiO}_{2}$ ) em $\mathrm{mg} \mathrm{L}^{-1} \mathrm{e}$ concentração dos íons dissolvidos em $\mu \mathrm{g} \mathrm{L}^{-1}$ das águas, segundo os períodos sazonais.

colóides) e quantidade de matéria orgânica, influenciam a química aquática (Elderfield et al. 1990 e Shiller 1997).

A soma da carga dissolvida, considerando os íons mais abundantes $\left(\mathrm{TDS}=\mathrm{Na}^{+}+\mathrm{K}^{+}+\mathrm{Mg}^{2+}+\mathrm{Ca}^{2+}+\mathrm{SiO}_{2}+\mathrm{Cl}^{-}\right.$ $+\mathrm{HCO}_{3}^{-}+\mathrm{NO}_{3}^{-}+\mathrm{SO}_{4}^{2-}$ ), é variável ao longo dos quatro períodos (Tabela 1 e Figura 2). Entre as drenagens o TDS é, em geral maior na água do Aripuaná no período chuvoso e na transição para a estiagem (entre 22 e $27 \mathrm{mg} \mathrm{L}^{-1}$ ) e no Acari e ou no Sucunduri nos outros dois períodos. É menor nas águas das drenagens menores (Ig1 e Ig2) e no Camaiú e Sucunduri na transição para a estiagem $\left(4,5\right.$ e $\left.7,0 \mathrm{mg} \mathrm{L}^{-1}\right)$. Contudo, a água do Sucunduri também tem baixo TDS na transição para a estiagem $\left(5,6 \mathrm{mg} \mathrm{L}^{-1}\right)$. Apesar de a condutividade estar relacionada à carga dissolvida, há correlação positiva desses dois parâmetros apenas no período chuvoso $(r=0,80)$ e na estiagem $(0,71)$.

A normalização do balanço de cargas inorgânicas (NBCI $=\left(\left(\sum^{+} \mu\right.\right.$ eq $\mathrm{L}^{-1}+\sum \mu$ eq $\left.\mathrm{L}^{-1}\right) /\left(\sum^{+} \mu\right.$ eq $\mathrm{L}^{-1}-\sum \mu$ eq $\left.\left.\mathrm{L}^{-1}\right) / 2\right)$ mostra, 
em geral excesso de ânions em consequência da elevada concentração em $\mathrm{HCO}_{3}$, exceto nas águas mais ácidas nos períodos chuvoso e transição para a estiagem quando a concentraçấo desse íon abaixo do limite de detecção aumenta a carga positiva (Tabela 1).

\section{DISCUSSÃO}

\section{Origem dos elementos dissolvidos nas águas}

A carga dissolvida nas águas dos rios, após a retirada da influência da água da chuva, permite estimar a origem dos elementos dissolvidos e examinar os mecanismos associados ao intemperismo das rochas (Stallard 1995, Gaillardet et al. 1997). A influência da água da chuva é determinada pelo método de Gaillardet et al. (1997) com a equaçáo $\mathrm{C}=\mathrm{Cx}_{\text {rio }}-$ $\left(\mathrm{Cx} / \mathrm{CCl}^{-}\right)_{\text {mar }} \mathrm{x} \mathrm{CCl}_{\text {rio }}^{-}$(onde $\mathrm{Cx}$ é a concentração do elemento e CCl- é a concentração de cloreto, ambos em $\mu \mathrm{mol} \mathrm{L}^{-1}$ ). Para tal foi obtida a média ponderada entre a composição química mensal das águas dos rios estudados e o índice pluviométrico (Tabela 2). Como não há evaporitos na região estudada (Reis 2006 e CPRM no prelo), todo o $\mathrm{Cl}^{-}$das águas foi considerado como proveniente da chuva a partir da evaporação da água do mar, cuja composiçáo média foi obtida de Berner e Berner (1987). Desse modo entre $14 \%$ do $\mathrm{Na}^{+}$na água do Acari e $100 \%$ na do Jatuarana é proveniente da chuva (Tabela 2). Há influência também no $\mathrm{SO}_{4}^{2-}$ entre $21 \%$ e $38 \%$, seguido do $\mathrm{Mg}^{2+}$ entre $2 \%$ e $19 \%$. Os demais íons dissolvidos $\left(\mathrm{K}^{+}, \mathrm{Ca}^{2+}\right.$, $\mathrm{SiO}_{2}, \mathrm{HCO}_{3}^{-}, \mathrm{NO}_{3}^{-}$) têm pouca a nenhuma influência da chuva em suas concentraçôes nas águas dos rios.

Utilizaram-se, para determinar a origem dos elementos, os principais tipos de rochas que constituem a crosta continental (silicáticas, carbonáticas e evaporitos) de Gaillardet et al. (1997), além daquelas que ocorrem na regiáo (CPRM no

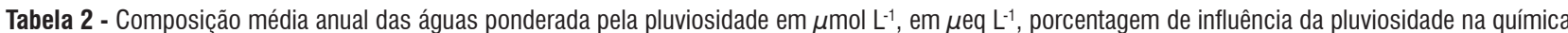
das águas e razões entre $\mathrm{Mg} / \mathrm{Na}, \mathrm{Ca} / \mathrm{Na}, \mathrm{Si} /(\mathrm{Na}+\mathrm{K})$ e soma de $\mathrm{Ca}+\mathrm{Mg}$ e $\mathrm{Na}+\mathrm{K}$.

\begin{tabular}{|c|c|c|c|c|c|c|c|c|c|c|}
\hline & Íons & Aripuanã & Jatuarana & $\lg 1$ & $\lg 2$ & Juma & Acari & Camaiú & Sucunduri & Média \\
\hline \multirow{9}{*}{$\begin{array}{l}\bar{T} \\
2 \\
2\end{array}$} & $\mathrm{Na}^{+}$ & $1.142,25$ & 137,39 & 152,31 & 547,38 & 568,67 & $1.147,46$ & 248,08 & 268,36 & 526,5 \\
\hline & $\mathrm{K}^{+}$ & $1.485,03$ & $1.279,40$ & 685,77 & $1.267,32$ & $1.582,11$ & $3.066,34$ & $2.102,01$ & $2.219,84$ & $1.485,03$ \\
\hline & $\mathrm{Ca}^{2+}$ & $1.043,26$ & $1.236,46$ & 157,29 & 619,61 & 919,43 & 823,13 & 121,66 & $1.136,21$ & 757,1 \\
\hline & $\mathrm{Mg}^{2+}$ & 487,19 & 437,27 & 141,37 & 116,66 & 397,93 & 382,04 & 173,12 & 661,02 & 349,6 \\
\hline & $\mathrm{SiO}_{2}$ & $4.395,25$ & $3.265,66$ & $2.415,61$ & $2.764,05$ & $3.160,83$ & $5.568,34$ & $2.716,74$ & $3.494,97$ & $3.472,7$ \\
\hline & $\mathrm{HCO}_{3}^{-}$ & $13.429,21$ & $5.647,45$ & $2.636,58$ & $2.511,93$ & $3.062,44$ & $9.846,52$ & $6.204,48$ & $5.670,65$ & $6.126,16$ \\
\hline & $\mathrm{Cl}^{\circ}$ & 325,47 & 293,04 & 247,95 & 326,53 & 374,41 & 297,68 & 307,54 & 226,42 & 299,88 \\
\hline & $\mathrm{NO}_{3}^{-}$ & $1.019,84$ & 630,23 & 469,14 & $1.732,49$ & 999,39 & 795,97 & $1.794,13$ & $1.583,91$ & $1.128,1$ \\
\hline & $\mathrm{SO}_{4}^{2-}$ & 180,99 & 200,33 & 90,73 & 141,41 & 237,31 & 150,31 & 128,35 & 146,71 & 159,5 \\
\hline $\mathrm{mg} \mathrm{L}^{-1}$ & TDS & 23,51 & 13,13 & 7,00 & 10,03 & 11,30 & 22,08 & 13,80 & 15,41 & 14,53 \\
\hline \multirow{10}{*}{$\begin{array}{l}\frac{\bar{J}}{\bar{O}} \\
\stackrel{E}{\Sigma}\end{array}$} & $\mathrm{Na}^{+}$ & 49,68 & 5,98 & 6,63 & 23,81 & 24,74 & 49,91 & 10,79 & 11,67 & 22,9 \\
\hline & $\mathrm{K}^{+}$ & 37,98 & 32,72 & 17,54 & 32,41 & 40,47 & 78,43 & 53,76 & 56,78 & 43,76 \\
\hline & $\mathrm{Ca}^{2+}$ & 26,03 & 30,85 & 3,92 & 15,46 & 22,94 & 20,54 & 3,04 & 28,35 & 18,89 \\
\hline & $\mathrm{Mg}^{2+}$ & 20,04 & 17,99 & 5,82 & 4,80 & 16,37 & 15,72 & 7,12 & 27,20 & 14,38 \\
\hline & $\mathrm{SiO}_{2}$ & 73,15 & 54,35 & 40,20 & 46,00 & 52,61 & 92,68 & 45,22 & 58,17 & 57,80 \\
\hline & $\mathrm{HCO}_{3}^{-}$ & 220,09 & 92,55 & 43,21 & 41,17 & 50,19 & 161,37 & 101,68 & 92,93 & 100,40 \\
\hline & $\mathrm{Cl}^{-}$ & 9,18 & 1,52 & 6,99 & 0,67 & 0,82 & 8,40 & 8,67 & 1,52 & 1,65 \\
\hline & $\mathrm{NO}_{3}^{-}$ & 16,45 & 10,16 & 7,57 & 27,94 & 16,12 & 12,84 & 28,94 & 25,55 & 18,19 \\
\hline & $\mathrm{SO}_{4}^{2-}$ & 1,88 & 2,09 & 0,94 & 1,47 & 2,47 & 1,56 & 1,34 & 1,53 & 1,66 \\
\hline & TDS & 454,49 & 254,96 & 132,82 & 202,28 & 236,46 & 441,44 & 260,56 & 308,56 & 286,45 \\
\hline \multirow{11}{*}{$\frac{\bar{I}}{\stackrel{I}{\Phi}}$} & $\mathrm{Na}^{+}$ & 49,68 & 5,98 & 6,63 & 23,81 & 24,74 & 49,91 & 10,79 & 11,67 & 22,90 \\
\hline & $\mathrm{K}^{+}$ & 37,98 & 32,72 & 17,54 & 32,41 & 40,47 & 78,43 & 53,76 & 56,78 & 43,76 \\
\hline & $\mathrm{Ca}^{2+}$ & 52,06 & 61,70 & 7,85 & 30,92 & 45,88 & 41,08 & 6,07 & 56,70 & 37,78 \\
\hline & $\mathrm{Mg}^{2+}$ & 40,09 & 35,98 & 11,63 & 9,60 & 32,74 & 31,44 & 14,25 & 54,39 & 28,77 \\
\hline & $\mathrm{SiO}_{2}$ & 73,15 & 54,35 & 40,20 & 46,00 & 52,61 & 92,68 & 45,22 & 58,17 & 57,80 \\
\hline & $\mathrm{HCO}_{3}^{-}$ & 220,09 & 92,55 & 43,21 & 41,17 & 50,19 & 161,37 & 101,68 & 92,93 & 100,40 \\
\hline & $\mathrm{Cl}^{-}$ & 9,18 & 8,27 & 6,99 & 9,21 & 10,56 & 8,40 & 8,67 & 6,39 & 8,46 \\
\hline & $\mathrm{NO}_{3}^{-}$ & 16,45 & 10,16 & 7,57 & 27,94 & 16,12 & 12,84 & 28,94 & 25,55 & 18,19 \\
\hline & $\mathrm{SO}_{4}^{2-}$ & 3,77 & 4,17 & 1,89 & 2,94 & 4,94 & 3,13 & 2,67 & 3,05 & 3,32 \\
\hline & ¿cátions & 179,82 & 123,58 & 43,65 & 86,48 & 143,83 & 167,79 & 84,87 & 152,21 & 164,83 \\
\hline & ¿ânions & 33,00 & 24,12 & 17,16 & 40,77 & 32,44 & 27,01 & 41,95 & 36,51 & 133,21 \\
\hline
\end{tabular}


Tabela 2 - Continuação

\begin{tabular}{|c|c|c|c|c|c|c|c|c|c|c|c|}
\hline & & Íons & Aripuanã & Jatuarana & $\lg 1$ & $\lg 2$ & Juma & Acari & Camaiú & Sucunduri & Média \\
\hline \multirow{17}{*}{ 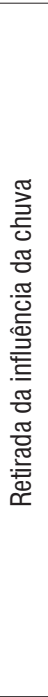 } & \multirow{15}{*}{$\frac{\bar{\Xi}}{\overline{\bar{O}}}$} & $\mathrm{Na}^{+}$ & 41,80 & $-1,12$ & 0,62 & 15,90 & 15,67 & 42,70 & 3,34 & 6,19 & 14,6 \\
\hline & & $\mathrm{K}^{+}$ & 37,81 & 32,57 & 17,41 & 32,24 & 40,27 & 78,27 & 53,60 & 56,66 & 32,1 \\
\hline & & $\mathrm{Ca}^{2+}$ & 25,86 & 30,70 & 3,79 & 15,29 & 22,74 & 20,38 & 2,87 & 28,23 & 19,7 \\
\hline & & $\mathrm{Mg}^{2+}$ & 19,15 & 17,19 & 5,14 & 3,90 & 15,34 & 14,90 & 6,28 & 26,58 & 12,1 \\
\hline & & $\mathrm{SiO}_{2}$ & 73,15 & 54,35 & 40,20 & 46,00 & 52,60 & 92,67 & 45,21 & 58,17 & 53,3 \\
\hline & & $\mathrm{HCO}_{3}^{-}$ & 220,05 & 92,52 & 43,18 & 41,13 & 50,15 & 161,34 & 101,65 & 92,91 & 89,4 \\
\hline & & $\mathrm{Cl}^{-}$ & 0,00 & 0,00 & 0,00 & 0,00 & 0,00 & 0,00 & 0,00 & 0,00 & 0,00 \\
\hline & & $\mathrm{NO}_{3}^{-}$ & 16,45 & 10,16 & 7,57 & 27,94 & 16,12 & 12,84 & 28,94 & 25,55 & 15,6 \\
\hline & & $\mathrm{SO}_{4}^{2-}$ & 1,41 & 1,66 & 0,58 & 1,00 & 1,92 & 1,13 & 0,89 & 1,20 & 1,3 \\
\hline & & TDS & 435,68 & 239,15 & 118,50 & 183,41 & 214,82 & 424,24 & 242,78 & 295,47 & 152,1 \\
\hline & & $\mathrm{Ca} / \mathrm{Na}$ & 0,62 & & 6,10 & 0,96 & 1,45 & 0,48 & 0,86 & 4,56 & 2,3 \\
\hline & & $\mathrm{Mg} / \mathrm{Na}$ & 0,46 & & 8,26 & 0,25 & 0,98 & 0,35 & 1,88 & 4,29 & 2,5 \\
\hline & & $\mathrm{Si} /(\mathrm{Na}+\mathrm{K})$ & 0,92 & 1,73 & 2,23 & 0,96 & 0,94 & 0,77 & 0,79 & 0,93 & 1,4 \\
\hline & & $\mathrm{Na}+\mathrm{K}$ & 79,62 & 31,45 & 18,03 & 48,15 & 55,94 & 120,97 & 56,95 & 62,85 & 46,6 \\
\hline & & $\mathrm{Ca}+\mathrm{Mg}$ & 45,01 & 47,88 & 8,93 & 19,19 & 38,09 & 35,28 & 9,15 & 54,80 & 31,8 \\
\hline & \multirow{2}{*}{$\mu \mathrm{g} \mathrm{L}^{-1}$} & $\sum$ cátions & 3.941 & 2.896 & 972 & 2.334 & 3.219 & 5.221 & 2.440 & 4.135 & 2.672 \\
\hline & & $\sum$ cátions $+\mathrm{SiO}_{2}$ & 8.336 & 6.161 & 3.387 & 5.098 & 6.380 & 10.789 & 5.157 & 7.630 & 5.872 \\
\hline \multirow{9}{*}{ 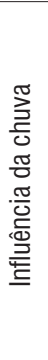 } & & $\mathrm{Na}^{+}$ & $16 \%$ & $100 \%$ & $91 \%$ & $33 \%$ & $37 \%$ & $14 \%$ & $69 \%$ & $47 \%$ & $59 \%$ \\
\hline & & $\mathrm{K}^{+}$ & $0 \%$ & $1 \%$ & $1 \%$ & $1 \%$ & $0 \%$ & $0 \%$ & $0 \%$ & $0 \%$ & $1 \%$ \\
\hline & & $\mathrm{Ca}^{2+}$ & $1 \%$ & $1 \%$ & $3 \%$ & $1 \%$ & $1 \%$ & $1 \%$ & $5 \%$ & $0 \%$ & $1 \%$ \\
\hline & & $\mathrm{Mg}^{2+}$ & $4 \%$ & $4 \%$ & $12 \%$ & $19 \%$ & $6 \%$ & $5 \%$ & $12 \%$ & $2 \%$ & $9 \%$ \\
\hline & & $\mathrm{SiO}_{2}$ & $0 \%$ & $0 \%$ & $0 \%$ & $0 \%$ & $0 \%$ & $0 \%$ & $0 \%$ & $0 \%$ & $0 \%$ \\
\hline & & $\mathrm{HCO}_{3}^{-}$ & $0 \%$ & $0 \%$ & $0 \%$ & $0 \%$ & $0 \%$ & $0 \%$ & $0 \%$ & $0 \%$ & $0 \%$ \\
\hline & & $\mathrm{Cl}^{-}$ & $100 \%$ & $100 \%$ & $100 \%$ & $100 \%$ & $100 \%$ & $100 \%$ & $100 \%$ & $100 \%$ & $100 \%$ \\
\hline & & $\mathrm{NO}_{3}^{-}$ & $0 \%$ & $0 \%$ & $0 \%$ & $0 \%$ & $0 \%$ & $0 \%$ & $0 \%$ & $0 \%$ & $0 \%$ \\
\hline & & $\mathrm{SO}_{4}^{2-}$ & $25 \%$ & $21 \%$ & $38 \%$ & $32 \%$ & $22 \%$ & $28 \%$ & $34 \%$ & $22 \%$ & $28 \%$ \\
\hline
\end{tabular}

prelo). Os dados mostram que apesar das rochas da região e que fazem parte do cráton Amazônico, também serem silicáticas, elas tem razóes $\mathrm{Mg} / \mathrm{Na}$ e $\mathrm{Ca} / \mathrm{Na}$ com variaçóes maiores que as de Gaillardet et al. (1997), o que amplia o campo desse tipo de rocha na região (Figura 3). Portanto, a superposição das águas, com razóes $\mathrm{Mg} / \mathrm{Na}$ entre 0,25 e 8,26 e Ca/Na entre 0,48 e 6,10 (Tabela 2), com as rochas da região, além das razóes $\mathrm{Si} /(\mathrm{Na}+\mathrm{K})$ entre 0,92 e 2.91 (Tabela 2), refletem a origem silicática para as águas (distinta das rochas carbonáticas e das evaporíticas com razóes $\mathrm{Ca} / \mathrm{Na}$ acima de 10 e abaixo de 1, respectivamente - Figura 3). Essas razóes e a soma das cargas positivas inferior a $179 \mu \mathrm{eq} \mathrm{L} \mathrm{L}^{-1}$ (rio Aripuanã - Tabela 2), que permite classificar as águas como extremamente diluídas ( $\sum^{+}<0,185$ meq L $L^{-1}-$ Meybeck, 2003), reflete o intenso intemperismo que ocorre na Amazônia e a baixa retenção de cátions que resulta na formação de gibbsita e caulinita (Stallard et al. 1995). Os valores de $\mathrm{SiO}_{2}$ nas águas inferior a $93 \mu$ moles $L^{-1}$ (rio Acari) (Tabela 2), apesar da influência da vegetação nesse elemento (Millot et al. 2002), também é similar as condiçóes de ambiente cratônico definido por Stallard (1995) entre 50 e $100 \mu$ moles de $\mathrm{SiO}_{2}$.

A somatória $\mathrm{Ca}+\mathrm{Mg}$ combinada com a de $\mathrm{Na}+\mathrm{K}$ (Figura 3), que também permite inferir sobre o tipo de ambiente drenado (Zakharova et al. 2007), separam as águas em três subambientes geoquímicos (Figura 3) que mantêm certa correlação com a geologia da região: 1) as dos rios Aripuanã, Jatuarana, Juma e Sucunduri com a soma $\mathrm{Ca}+\mathrm{Mg}$ elevada, sugere aporte de rochas com maior proporção de plagioclásio (pequena ocorrência de carbonatos, portadores de Ca e $\mathrm{Mg}$, foram identificados por Reis (2006) a montante do rio Sucunduri); 2) as dos Ig1, Ig2 e Camaiú, com baixa soma $\mathrm{Ca}+\mathrm{Mg}$ e $\mathrm{Na}+\mathrm{K}$, sugere rochas pobres nesses elementos e, consequentemente com mais quartzo que corresponderiam as sedimentares conforme a geologia da região; e 3) as do Acari com soma de $\mathrm{Na}+\mathrm{K}$ mais elevada representaria as rochas vulcânicas já que a montante do local amostrado ocorre esse tipo de rocha (Reis 2006).

\section{Fluxo de elementos e consumo de $\mathrm{CO}_{2}$}

O fluxo de elementos para as soluçóes, que resulta do intemperismo químico das rochas, é determinado com base na área da bacia, na vazão e na carga química de cátions, segundo a equação:

$\mathrm{F}\left(\right.$ ton $\mathrm{km}^{2}$ ano $\left.^{-1}\right)=\left[\sum\right.$ Cátions $\left(\mathrm{em} \mathrm{mg} \mathrm{L}^{-1}\right) \mathrm{x}$ vazão média $\left.\left(\mathrm{m}^{3} \mathrm{ano}^{-1}\right)\right] /\left[\right.$ área da bacia $\left.\left(\mathrm{km}^{2}\right) \times 0,0864\right]$ (o fator 0,0864 é para correção das unidades de cálculo para toneladas ano) (Gaillardet et al. 1997). 

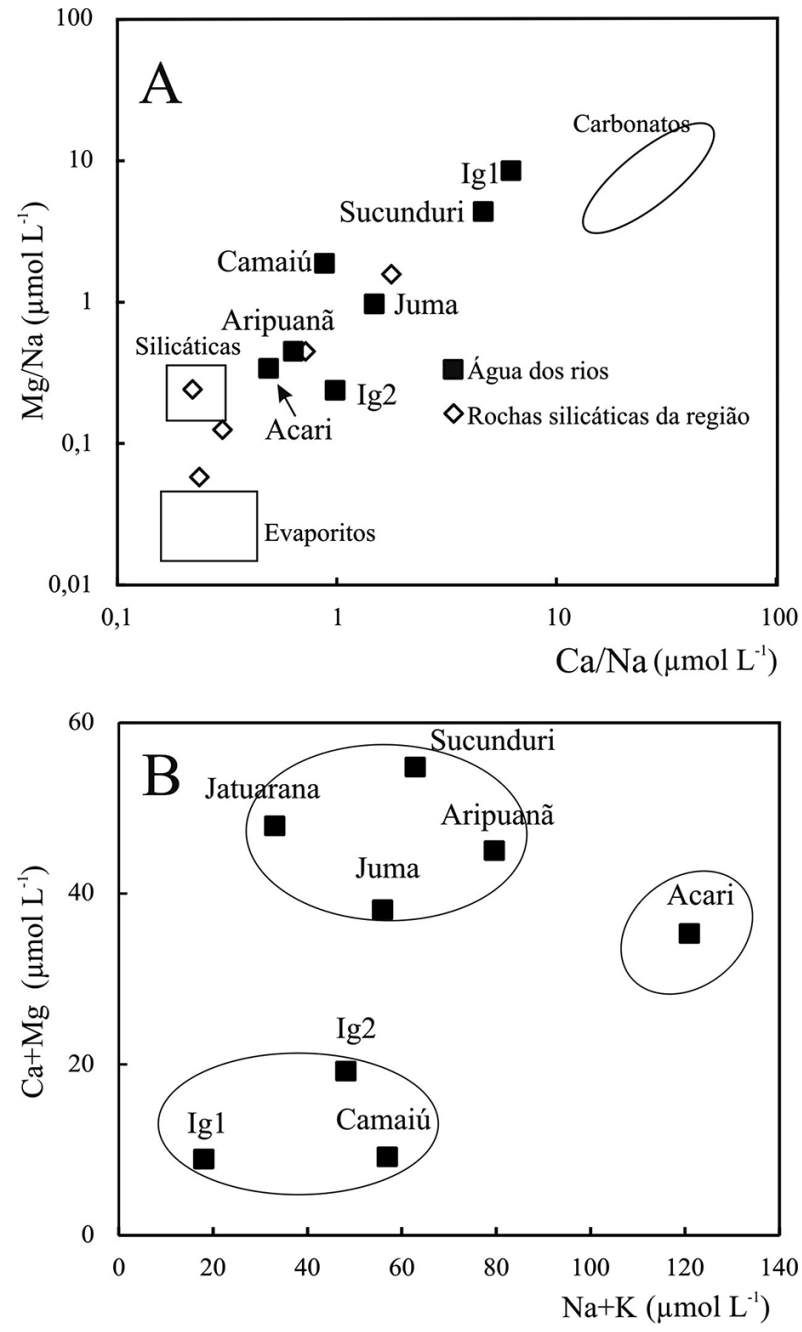

Figura 3 - Razão $\mathrm{Ca} / \mathrm{Na}$ versus $\mathrm{Mg} / \mathrm{Na}(\mathrm{A})$ e soma $\mathrm{Ca}+\mathrm{Mg}$ versus $\mathrm{Na}+\mathrm{K}$ (B) em $\mu \mathrm{mol} \mathrm{L}^{-1}$ após a retirada da influência da água da chuva em comparação com os campos das rochas carbonáticas, silicáticas e evaporíticas. Todo 0 $\mathrm{Na}$ das águas do rio Jatuarana tem origem atmosférica 0 que impossibilita identificar sua associação com o ambiente geológico do diagrama A.

Esse cálculo foi feito apenas para os rios Aripuaná, Acari e Sucunduri onde há dados disponíveis de vazão (2.925, 185 e $407 \mathrm{~m}^{3} \mathrm{~s}^{-1}$ dia, respectivamente) e área (109.000, 4.970 e $12.700 \mathrm{~km}^{2}$, respectivamente) ambos obtidos em www. ore-hybam.org. A carga de cátions é respectivamente 3,94, 5,22 e 4,13 $\mathrm{mg} \mathrm{L}^{-1}$ (Tabela 2), o que indica que os rios Aripuanã, Acari e Sucunduri exportam 3,34, 6,13 e 4,18 ton de cátions $\mathrm{km}^{-2}$ ano $^{-1}$ para o rio Madeira, respectivamente. Se considerarmos também o conteúdo de $\mathrm{SiO}_{2}$, os valores do fluxo dobram $\left(7,05,12,67\right.$ e 7,71 ton de cátions $+\mathrm{SiO}_{2}$ $\mathrm{km}^{-2} \mathrm{ano}^{-1}$ respectivamente). Esses fluxos são superiores ao do rio Negro e inferiores ao do rio Solimóes e Madeira, mas se aproximam do fluxo dos rios Uatumá (ou Urucará), Trombetas e Tapajós (Gaillardet et al. 1997), que também têm baixo conteúdo de material em suspensão.

Em função do fluxo de cátions e a densidade média das rochas silicáticas $\left(2,7 \mathrm{~g} \mathrm{~cm}^{-3}\right)$ determina-se a taxa de erosão química (Xu et al. 2010) a qual é de 1,24, 1,71 e 1,55 m por milhão de anos, respectivamente nos rios Aripuanã, Acari e Sucunduri. Essa taxa está entre a faixa estimada por Stallard (1995) para regiôes intracratônicas (1 a 5 m por milhão de anos), mas considerada baixa quando comparada com a de Edmond et al. (1995) que encontrou entre 5 e $20 \mathrm{~m}$ por milhão de anos no Cráton das Guianas. Essa baixa taxa é consequência dos rios de água preta quase não transportarem material em suspensão e da estabilidade tectônica da área. Segundo Edmond et al. (1995) e Stallard (1995) a taxa de erosão não está ligada diretamente a condição topográfica, mas à tectônica e entalhamento da drenagem. Em regióes cratônicas estáveis, o gradiente hidráulico é baixo e o intemperismo, que promove a formação de caulinita, gibbsita, óxi-hidróxidos de Fe e a dissoluçáo do quartzo (Stallard e Edmond 1983 e 1987), forma um manto protetor que dificulta a alteração das rochas o que gera águas pobres em íons solúveis, mas ricas em Si (Edmond et al. 1995). Entretanto, o fluxo e a taxa de erosão química mais elevada no rio Acari reflete maior facilidade de intemperismo das rochas vulcânicas em relação às demais que ocorrem na regiáo.

Durante o intemperismo das rochas há consumo de $\mathrm{CO}_{2}$ o qual é representado pelo $\mathrm{HCO}_{3}{ }^{-}$dissolvido na água, que corresponde a 0,22, 0,16 e 0,09 mol L-1 nos rios Aripuaná, Acari e Sucunduri respectivamente (Tabela 2) (Gaillardet et al. 1997). Foi constatado um consumo de $\mathrm{CO}_{2}$ de 20,30, 0,94 e $1,1910^{9} \mathrm{~mol} \mathrm{ano}^{-1}$ no intemperismo das rochas das respectivas bacias. Os fluxos são compatíveis com os baixos valores de $\mathrm{CO}_{2}$ encontrados em rios de águas pretas como o Negro (Gaillardet et al. 1997). Esse baixo consumo é consequência do $\mathrm{HCO}_{3}$ dissolvido nas águas ser proveniente, exclusivamente do $\mathrm{CO}_{2}$ atmosférico já que não foi identificada contribuição de rochas carbonáticas. O consumo dos três rios estudados é muito inferior aos rios Solimóes e Madeira (Gaillardet et al. 1997).

\section{CONCLUSÃO}

As águas dos rios do SE do Amazonas, que drenam o Escudo Brasileiro são pretas, ácidas e pouco condutivas. São muito diluídas, classificadas como bicarbonatadas-silícicas e resultam da intensa lixiviação nas condiçôes tropicais quentes e úmidas da Amazônia. São mais concentradas no período de estiagem e na transição para o período chuvoso o indica a influência do regime hidrológico da região. Foram identificados três subambientes geoquímicos dentro do macro ambiente do sudoeste da Amazônia que, provavelmente refletem as variaçóes litológicas entre as bacias. As baixas taxas 
de exportaçấo de cátions (entre 3,34 e 6,13 ton de cátions $\mathrm{km}^{-2}$ ano ${ }^{-1}$ ) e de erosão química (entre 1,2 e 2,4 m por milhão de anos) em relação a rios de águas brancas com elevado conteúdo de material em suspensão, assim como o consumo de $\mathrm{CO}_{2}$ (entre 0,9 e 20,3 $10^{9} \mathrm{~mol} \mathrm{ano}^{-1}$ ), reflete a estabilidade tectônica da regiáo e o manto intempérico que dificulta, mas não impede a interação da água com o substrato rochoso.

\section{AGRADECIMENTOS}

Ao programa de pós-graduação em Geociências da UFAM pelo apoio laboratorial; a CAPES pela bolsa ao primeiro autor; ao CNPq pela bolsa de produtividade ao segundo autor e ao projeto Casadinho/CNPq proc. no. 620039/2008-6 pelo apoio financeiro. Aos revisores pelas suas correçôes e sugestōes.

\section{BIBLIOGRAFIA CITADA}

Allégre, C.J.; Dupré, B.; Négrel, P.; Gaillardet, J. 1996. Sr-Nd$\mathrm{Pb}$ isotopes systematics in Amazon and Congo river systems: Constrain about erosion processes. Chemical Geology, 131: 93-112.

Berner, E.K.; Berner, R.A. 1987. The global water cycle: geochemistry and environment. Englewood Clifs, New Jersey. 397 pp.

Companhia de Pesquisas e Recursos Minerais CPRM. Geologia e recursos minerais da folha Sumaúma - SB.20-Z-D. Projeto Sumaúma-Roosevelt-Mutum. Relatório Final. MME/SGTM, CPRM, Manaus, 260 pp. (no prelo).

Drever, J.I. 1997. The Geochemistry of Natural Waters Surface and Groundwater Environments. Prentice Hall. USA, 460 pp.

Edmond, J.M; Palmer, M.R; Measures, C.I; Stallard, R.F. 1995. The fluvial geochemistry and denudation rate of the Guayana Shield in Venezuela, Colombia and Brazil. Geochimica et Cosmochimica Acta, 59: 3301-3325.

Elderfield, H.; Upstill-Goddard, R.; Sholkovitz, E.R. 1990. The rare earth elements in rivers, estuaries, and coastal seas and their significance to the composition of ocean waters. Geochemical et Cosmochemical Acta, 54: 971-991.

Gaillardet, J.; Dupré, B.; Allègre, C.J.; Négrel P. 1997, Chemical and physical denudation in the Amazon River Basin. Chemical Geology, 142: 141-173.

Meybeck, M. 2003. Global occurrence of major elements in rivers p.207-223. In: Hooland, H.D. and Turekien K.K. (eds) Treatise of geochemistry. v.5. Elsevier. 207-223

Millot, R; Gaillardet, J; Dupré, B; Allegre, C. J. 2002. The global control of silicate weathering rates and the coupling with physical erosion: new insights from rivers of the Canadian Shield. Earth and Planetary Science Letters, 196: 83-98.
Mortati, J; Probst, J. L. 2003. Silicate rock weathering and atmospheric/soil $\mathrm{CO}_{2}$ uptake in the Amazon Basin estimated from river water geochemistry: seasonal and spatial variations. Chemical Geology, 197: 177-196.

www.ore-hybam.org. The Environmental Research Observatory (ORE) HYBAM (Geodynamical, hydrological and biogeochemical control of erosion/alteration and material transport in the Amazon basin). Acesso 15/10/2011.

Picouet, C.; Dupré, B.; Orange, D.; Valladon, M. 2002. Major and trace elements geochemistry in the upper Niger river (mali): physical and chemical weathering rates and $\mathrm{CO}_{2}$ consumption. Chemical Geology, 185: 93-124.

Reis, N.J. 2006. Projeto rochas carbonáticas de Apui - Amazonas. Relatório Final. CPRM. Serviço Geológico do Brasil. Manaus. 60 pp..

Santos, F.L.G 2009. Caracterização química e definição de protocolo analítico para tratamento de efluentes usados em sistema de irrigação na agricultura. Dissertação de mestrado. Centro de Energia Nuclear na Agricultura, Universidade de São Paulo, Piracicaba, 79 pp.

Shiller, A.M. 1997. Dissolved trace elements in the Mississippi river: Seasonal, interannaual, and decadal variability. Geochimica et Cosmochimica Acta, 61: 4321-4330.

Smolders, A.J.P., Hudson-Edwards, K.A., Van der Velde, G., Roelofs, J.G.M. 2004. Controls on water chemistry of Pilcomayo river (Bolivia, South-America). Applied Geochemistry, 19: 1745-1758.

Stallard. R.F; Edmond, J.M. 1983. Geochemistry of the Amazon 2. The influence of geology and weathering environment on the dissolved load. Journal of Geophysical Research, 88: 9671-9688.

Stallard, R.F.; Edmond, J.M. 1987, Geochemistry of the Amazon 3. Weathering chemistry and limits to dissolved inputs. Journal of the Geophysical Research, 92: 8293-8302.

Stallard, R.F. 1995. Tectonic, environmental, and human aspects of weathering and erosion: A global review using steady-state perspective. Annual Review Earth and Planetary Science, 23: 11-39.

Xu, Z.; Lui, C-Q. 2010. Water geochemistry of the Xijiang basin rivers, South China: Chemical weathering and $\mathrm{CO}_{2}$ consumption. Applied Geochemistry, 25: 1603-1614.

Zakharova, E.A.; Pokrovsky, O.S.; Dupré, B.; Gaillardet, J.; Efimova, 2007. Chemical weathering of silicate rocks in Karelia region and Kola peninsula, NW Russia: assessing the effect of rock composition, wetlands and vegetation. Chemical Geology, 242: 255-277.

Recebido em 28/02/2012

Aceito em 04/08/2012 